\title{
Concept characteristics and variation in lexical diversity in two Dutch dialect areas
}

\author{
Karlien Franco (QLVL, University of Leuven) - karlien.franco@kuleuven.be - ORCID: 0000-0001-6499-265X \\ Dirk Geeraerts (QLVL, University of Leuven) - dirk.geeraerts@kuleuven.be \\ Dirk Speelman (QLVL, University of Leuven) - dirk.speelman@kuleuven.be \\ Roeland van Hout (Radboud University Nijmegen) - r.vanhout@let.ru.nl
}




\title{
Concept characteristics and variation in lexical diversity in two Dutch dialect areas
}

\author{
Abstract \\ Lexical diversity, the amount of lexical variation shown by a particular concept, varies between concepts. \\ For the concept DRUNK, for instance, nearly 3000 English expressions exist, including blitzed, intoxicated, \\ and hammered. For the concept SOBER, however, a significantly smaller number of lexical items is \\ available, like sober or abstinent. While earlier variation studies have revealed that meaning-related \\ concept characteristics correlate with the amount of lexical variation, these studies were limited in \\ scope, being restricted to one semantic field and to one dialect area, that of the Limburgish dialects of \\ Dutch (Geeraerts and Speelman 2010, Speelman and Geeraerts 2007, 2008). In this paper, we investigate \\ whether the impact of concept characteristics, viz. vagueness, lack of salience and proneness to affect, is \\ manifest in a similar way in other dialects and other semantic fields. In particular, by extending the scope \\ of the earlier studies to other carefully selected semantic fields, we investigate the generalizability of the \\ impact of concept characteristics to the lexicon as a whole. The quantitative approach that we employ to \\ measure concept characteristics and lexical diversity methodologically advances the study of linguistic \\ variation. Theoretically, this paper contributes to the further development of Cognitive Sociolinguistics \\ by showcasing how meaning can be a source of lexical diversity. \\ Keywords \\ lexical diversity, lexical variation, dialectology, cognitive sociolinguistics, Dutch
}




\section{Introduction}

Lexical diversity, the amount of lexical variation a particular concept shows, can differ between concepts. For the concept DRUNK ${ }^{1}$, for instance, nearly 3000 English expressions exist, including blitzed, intoxicated, hammered and I'm not as think as you drunk I am (Dickson 2009, cited in Lillo 2009). For the concept SOBER, however, a significantly smaller number of lexical items is available, like sober or abstinent. Generally, studies in variational linguistics assume that this type of lexical variation is influenced by lectal features, like the region of the language user (e.g. Grieve et al. 2011, Wieling et al. 2014). However, as is apparent from this example, variation in lexical diversity can also be influenced by characteristics of the concepts to be expressed: for instance, concepts that are prone to affect show more variation (Allan and Burridge 1988, 2006).

Crucially, the perspective on meaning and categorization in Cognitive Linguistics $(\mathrm{CL})$ suggests that other types of meaning-related concept ${ }^{2}$ characteristics may also affect lexical diversity. Geeraerts and Speelman $(2010)$ and Speelman and Geeraerts $(2007,2008)$ already found evidence for the interaction between features related to the prototype-theoretical organization of the lexicon and lexical diversity. First, they demonstrated that concepts that are more salient, i.e. highly familiar concepts that are wired in very strongly in the mind of a language user, show significantly less variation. Second, their results also indicated that concepts that are vague, i.e. fuzzy at the edges and difficult to distinguish from associated concepts, show significantly more variation. ${ }^{3}$ However, these studies only examined the influence of these meaning-related features in one semantic field (viz. the human body) and in one dialect area (viz. the Limburgish dialect area of Dutch). As a result, some further questions remain unanswered: Do concept characteristics like vagueness, salience and affect influence lexical diversity in semantic fields other than the human body? Is the effect of the concept characteristics stable and equally strong in every semantic field? Can we establish that such features impact lexical variation in the same way in dialect areas other than the Limburgish region as well?

The aim of this paper is, therefore, to examine to which extent the influence of the concept characteristics distinguished in the previous studies is generalizable, in a double sense: by including concepts from other types of semantic fields in the analysis, and by broadening the geographical scope of the investigation through the inclusion of the Brabantic dialect area of Dutch. We will investigate the generalizability of the impact of concept characteristics in the following way: is their impact stable and independent from both semantic field and dialect area and, if not, are differences categorical (the effect of concept characteristics is absent or present) or gradual (their effect differs in strength depending on semantic field and/or dialect area)?

\footnotetext{
${ }^{1}$ In this paper, SMALL CAPS are used to indicate concepts, while italics are used for the lexical item used to refer to these concepts.

${ }^{2}$ We use 'meaning' in a slightly broader sense than 'concept': while the latter may be defined as the denotational sense of a word, the former also includes additional semantic characteristics that may be associated with the concept (such as its degree of vagueness).

${ }^{3}$ Additionally, Speelman \& Geeraerts (2008) showed that taking these concept characteristics into account improves the quality of dialectometric distance measures.
} 
That the effects should be pervasive is indeed not self-evident. On the one hand, with regard to the geographic dimension, it is possible that the amount of lexical diversity differs between dialect areas. For instance, the Limburgish region, which forms the area of investigation of the previous studies by Geeraerts and Speelman, is a rural area with, on average, large geographical distances between the locations. Thus, it may be the case that in regions where geographical differences are generally smaller, or where there is more urbanization, we find less lexical diversity overall due to lexical levelling (e.g. Milroy 2002, Trudgill 2011). On the other hand, with regard to the semantic dimension, different fields may behave differently. For instance, names for children's games are notoriously diversified, due to the fact that child language is highly imaginative and creative (Weijnen 1966: 336, Pickl 2013). In contrast, a field like religion is probably prone to less variability, because it is based on a highly standardized framework, accompanied by specific concepts and their corresponding names which are often directly borrowed into (dialectal) varieties. Thus, the impact of the concept characteristics may be unstable or may shift if other types of concepts are included in the analysis. More specifically, the human body concepts that were included previously are relatively concrete and universal (Lakoff and Johnson 1980 and see below). However, the degree of concreteness and of universality of a concept may in itself interact with the way these concepts are processed and, thus, possibly with the amount of lexical diversity in dialect data. Consequently, there are a number of interaction effects that we may find: the impact of the concept characteristics may be insignificant in other types of semantic fields, their strength or effect size may be larger or smaller, or their impact may be of a different nature. The use of a larger and more diverse dataset and a more elaborate modelling procedure allow us to examine the generalizability of these effects to the lexicon as a whole. Our results will show that, although there are general differences in the amount of lexical diversity between the two dialect areas and differences in the strength of concept characteristics between semantic fields, overall, the concept characteristics significantly affect variation in the lexicon as a whole.

More generally, we intend to contribute to the further development of Cognitive Sociolinguistics (Kristiansen and Dirven 2008, Geeraerts et al. 2010 and Pütz et al. 2014) by adopting an onomasiological perspective to examine variation in the dialect lexicon. On the one hand, the added value of complementing semasiological research into lexical variation (i.e. research on 'meaning': examining the meanings that a linguistic construction can take) with an onomasiological approach (i.e. research on 'naming': investigating which names can be used to refer to a particular referent), was first made explicit in Geeraerts et al. (1994; further developments include Daems et al. 2015, Geeraerts et al. 1999, Heylen and Ruette 2013, Soares da Silva 2010, Speelman et al. 2003 and Zenner et al. 2012). We contribute to this research paradigm by showing that investigating a linguistic variety that has been under-researched in CL, viz. the dialect lexicon (exceptions include Swanenberg 2000 and Szelid and Geeraerts 2008), using an onomasiological approach offers new insights into the structure of linguistic variability. On the other hand, we open up a new line of research for studies in Cognitive Sociolinguistics and CL at large. More specifically, the study of language-internal variation from a cognitive linguistic point of view has been characterized as focusing on the 'variation of meaning' (the lectal and contextual variability of the meaningful categorization and construal phenomena that lie at the core of $\mathrm{CL}$ ) and the 'meaning of variation' (the categorization and cognitive representation of linguistic variation; see Geeraerts et al. 2010: 6-10). With the present paper, we want to draw attention to a third perspective on the interaction 
between meaning and variation, viz. 'variation through meaning': how the amount of variation in the expression of a concept is influenced by the characteristics of that concept. Finally, our quantitative approach can methodologically advance the study of linguistic variation in CL because the data and techniques we use to gauge characteristics of concepts can also be applied to other types of research questions.

Before turning to a more precise definition and operationalization of the concept characteristics in section 3 , section 2 sketches the datasets used in this paper. Section 4 presents the quantification of lexical diversity, the dependent variable in the analysis. The results are discussed in section 5 . Section 6 rounds off this paper with a conclusion.

\section{Data}

To examine whether the influence of concept characteristics on lexical diversity is generalizable across different dialect regions, we include data from the digitized databases of two large-scale dialect dictionaries of Dutch, viz. the Woordenboek van de Brabantse dialecten 'Dictionary of the Brabantic Dialects' (WBD) and the Woordenboek van de Limburgse dialecten 'Dictionary of the Limburgish Dialects' (WLD). The latter dictionary was also used in the studies by Geeraerts and Speelman mentioned earlier. A big advantage of these dictionaries is that they are onomasiologically organized, containing all the lexical dialect variants available in the Brabantic and Limburgish dialect areas for a large number of concepts. Each dictionary consists of three large parts, (1) agrarian terminology, (2) specialized nonagrarian terminology and (3) general vocabulary, but for practical reasons we only include data from the third part. Part 3 is further subdivided into four sections, which each consist of three or four thematic volumes that each represent a semantic field, like 'the human body', 'the house', 'society, school \& education', and 'birds'. To select the semantic fields that are included in the analysis, we fully rely on the way the concepts and semantic fields are delineated in the dictionary, i.e. on the manner in which the editors of the WBD and WLD carve up the lexical data into concepts (entities of meaning) and semantic fields (sets of thematically related concepts). ${ }^{4}$

As we are examining the effect of concept characteristics on the number of lexical variants that are available per concept, it is important that the data were collected systematically. For this reason, we restrict attention to the dialectal data in the databases that were collected by means of questionnaires distributed throughout the Brabantic and Limburgish dialect area, predominantly between 1960 and

\footnotetext{
${ }^{4}$ The same procedure was followed in the earlier studies by Geeraerts and Speelman. However, a reviewer correctly points out that we could have used some other way to examine the relationship between the lexical diversity in the basic material (i.e. the lexical items, regardless of which concept/semantic field they are attributed to by the lexicographers) and the structure of the lexicon, characterized by differences in salience and vagueness. However, there are two reasons why our approach has merit. First, the fieldworkers and lexicographers working on the WBD and WLD were well-trained dialectologists, who were very familiar with the Brabantic and Limburgish language and culture. As a result, we trust that their intuitions about the organization of the material they worked with, reflect the natural patterns to a large extent. Second, as the data were collected decades ago, we fear that imposing some other a priori defined structure on the data may result in a bias we wish to avoid (e.g. towards modern-day society). Furthermore, this would entail taking an additional step (viz. not only analyzing the relationship between variation in lexical diversity and the structure of the lexicon, but also examining the conceptualization of a concept in a dictionary). This falls outside the scope of our paper.
} 
$1990 .^{5}$ This means that older and less systematically collected data that were added to the dictionaries are excluded from the analysis.

Table 1: Example of the relevant columns from the semantic field 'the house' in the WBD

\begin{tabular}{|c|c|c|c|}
\hline concept & lexical variant & questionnaire & location \\
\hline $\begin{array}{l}\text { aanhitsen } \\
\text { 'to provoke a dog' }\end{array}$ & aanhiksen & N 83 (1981) & Baarle-Nassau \\
\hline $\begin{array}{l}\text { aanhitsen } \\
\text { 'to provoke a dog' }\end{array}$ & aanhissen & N 02 (1960) & Morkhoven \\
\hline $\begin{array}{l}\text { aanhitsen } \\
\text { 'to provoke a dog' }\end{array}$ & aanhissen & N 02 (1960) & Heist-op-den-Berg \\
\hline $\begin{array}{l}\text { aanhitsen } \\
\text { 'to provoke a dog' }\end{array}$ & hitsen & N 83 (1981) & Schaft \\
\hline $\begin{array}{l}\text { aanhitsen } \\
\text { 'to provoke a dog' }\end{array}$ & hitsen & N 83 (1981) & Nieuwrode \\
\hline $\begin{array}{l}\text { aanhitsen } \\
\text { 'to provoke a dog' }\end{array}$ & kissen & N 83 (1981) & Bergen op Zoom \\
\hline $\begin{array}{l}\text { aanhitsen } \\
\text { 'to provoke a dog' }\end{array}$ & ophitsen & N 83 (1981) & Bergen op Zoom \\
\hline $\begin{array}{l}\text { aanhitsen } \\
\text { 'to provoke a dog' }\end{array}$ & kissen & N 83 (1981) & s-Hertogenbosch \\
\hline $\begin{array}{l}\text { aanhitsen } \\
\text { 'to provoke a dog' }\end{array}$ & vals maken & N 83 (1981) & Mierlo-Hout \\
\hline$\ldots$ & $\ldots$ & $\ldots$ & $\ldots$ \\
\hline $\begin{array}{l}\text { emmer } \\
\text { 'bucket' }\end{array}$ & aker & N 12 (1961) & Heverlee \\
\hline $\begin{array}{l}\text { emmer } \\
\text { 'bucket' }\end{array}$ & aker & N 12 (1961) & Heverlee \\
\hline $\begin{array}{l}\text { emmer } \\
\text { 'bucket' }\end{array}$ & bronemmer & N 12 (1961) & St-Agatha-Berchem \\
\hline $\begin{array}{l}\text { emmer } \\
\text { 'bucket' }\end{array}$ & bronemmer & N 12 (1961) & Vilvoorde \\
\hline $\begin{array}{l}\text { emmer } \\
\text { 'bucket' }\end{array}$ & emmer & N 12 (1961) & Puurs \\
\hline $\begin{array}{l}\text { emmer } \\
\text { 'bucket' }\end{array}$ & emmer & N 12 (1961) & Londerzeel \\
\hline
\end{tabular}

Table 1 shows an example of the relevant columns of the databases, from the semantic field 'the house' in the WBD. The first column shows the concept for which information is available. The second column contains the lexical variant, a dutchified form of the dialect response of a respondent. In the third column, the questionnaire that was used to elicit this response is identified and in the final column, the location where the lexical variant was found, is presented. For some locations, more than one response is available.

\footnotetext{
${ }^{5} 94 \%$ of these questionnaire data were collected between 1960 and 1990, but follow-up questionnaires to elicit
} data for concepts for which a limited amount of data was available, were distributed between 1991 and 2002. 
To examine the effect of the concept characteristics in semantic fields other than 'the human body', we take into account five other semantic fields. We select semantic fields on the basis of two dimensions. This allows us to examine whether differences that may show up between semantic fields can be explained by these criteria. First, we include a social dimension, viz. whether a semantic field is universal, related to domestic life, or to supralocal societal phenomena. The second dimension concerns the average degree of concreteness of a semantic field, which we operationalize as the mean concreteness of the concepts belonging to the field.

The first dimension is included following the results obtained by Pickl (2013). He showed that in German dialect data, the chance of finding lexical levelling (i.e. a low degree of diversity) is higher for concepts relating to semantic fields that are socially relevant on a supralocal scale, rather than domestic and locally bound. For instance, socially relevant expressions with a phatic meaning, like salutations, are less prone to geographical variation due to the fact that they are used in many conversations, including to communicate with less familiar speakers. In contrast, expressions from semantic fields belonging to domestic life, like the household, are, according to Pickl, less prone to spatial diffusion. The explanation is that household objects and actions are stationary and, therefore, less supralocally relevant. Because these concepts are less frequently discussed by speakers who are mobile when performing the activity (e.g. doing the dishes), they show more lexical diversity. Aside from societal and domestic concepts, we also include universal concepts, because a universal semantic field (viz. 'the human body') was used in the earlier studies. Even though these concepts are not included in Pickl's framework, we can assume that they will show little variation (cf. Swadesh 1955): they are universal and salient for every human being (Lakoff and Johnson 1980).

To select semantic fields that differ along this first dimension, we rely on the organization of the dictionaries into sections and volumes. Part 3 of the dictionaries consist of four sections: (1) man as an individual, (2) domestic life, (3) community life and (4) the world versus man, which are organized along an expansional axis leading from individuals over society to people's relationship with the outside world. We select one volume from sections 1, 2 and 3, but exclude data from section 4, which contains the lexicon of the natural world: plants, birds and other wild animals, and the physical and abstract world (e.g. weather phenomena, time and space). ${ }^{6}$ Importantly, the semantic fields that we use for the individual category (from section 1) mostly contain universal concepts.

The second dimension is included for exploratory purposes. It is related to research in psycholinguistics, which shows that concrete words are easier to process and to recognise than more abstract words (Gorman 1961, Hargis and Gickling 1978, Paivio 1986). As a result, the advantages in the processing of words for concrete concepts may correlate with a larger degree of psychological wiring in of these concepts, which may in turn interact with the amount of lexical variation in the dialect data under scrutiny.

\footnotetext{
${ }^{6}$ The semantic fields that we include do not completely correspond to the semantic fields distinguished in Pickl's framework. More specifically, in our data, concepts concerning family \& sexuality are considered as part of domestic life. However, in Pickl's view, some of these concepts, specifically the kinship terms, are communicatively relevant on a supralocal scale (p. 73).
} 
To determine the degree to which a semantic field contains, on average, a larger amount of concrete concepts, we rely on word ratings for 30000 Dutch words collected by Brysbaert et al. (2014). ${ }^{7}$ These ratings range from 1 (very abstract) to 5 (very concrete). For each of the three sections of the dictionaries that are included in the analysis, we select one semantic field with a low value for mean concreteness and one with a high value for mean concreteness. Table 2 shows an overview of all the semantic fields per section and the mean concreteness rating per semantic field. However, not every concept from the dictionaries is available in the data from Brysbaert and colleagues. The proportion of concepts for which ratings are available per semantic field is shown in the final column. These columns, therefore, give a modest, approximative indication of the degree of confidence for the concreteness ratings. In general, for the societal concepts, concreteness ratings are available for fewer concepts. This may be a result of the fact that these concepts are prone to cultural change: the dictionary data were collected in the final half of the $20^{\text {th }}$ century, but the data from Brysbaert and colleagues were elicited recently.

Table 2: Mean concreteness and proportion of available concepts on the basis of Brysbaert et al. (2014) in the four sections of part 3 (general vocabulary) in the WLD

\begin{tabular}{|c|c|c|c|}
\hline section & semantic field & mean concreteness & $\begin{array}{l}\text { proportion of concepts } \\
\text { found in Brysbaert et al. } \\
\text { (2014) }\end{array}$ \\
\hline \multirow{4}{*}{$\begin{array}{l}\text { 1. man as an } \\
\text { individual }\end{array}$} & the human body & 4.390 & 0.590 \\
\hline & physical motions \& health & 3.677 & 0.612 \\
\hline & clothing \& personal hygiene & 4.316 & 0.208 \\
\hline & personality \& feelings & 2.347 & 0.579 \\
\hline \multirow[t]{3}{*}{ 2. domestic life } & the house & 4.345 & 0.449 \\
\hline & family \& sexuality & 3.359 & 0.488 \\
\hline & food \& drink & 3.967 & 0.487 \\
\hline \multirow[t]{3}{*}{ 3. community life } & society, school \& education & 3.260 & 0.580 \\
\hline & celebration \& entertainment & 3.772 & 0.193 \\
\hline & church \& religion & 2.988 & 0.204 \\
\hline \multirow{4}{*}{$\begin{array}{l}\text { 4. the world versus } \\
\text { man }\end{array}$} & fauna: birds & 4.051 & 0.347 \\
\hline & fauna: other animals & 4.453 & 0.382 \\
\hline & Flora & 4.207 & 0.222 \\
\hline & the physical \& abstract world & 3.755 & 0.237 \\
\hline
\end{tabular}

\footnotetext{
${ }^{7}$ The data from Brysbaert et al. (2014) are collected at the level of the word in standard Dutch. Following the authors, we assume that these standard Dutch variants reflect the degree of concreteness of the concept designated by the words to a large extent. We solely rely on names for concepts that are identical to the words available in the concreteness data. Although this may influence the mean values to some extent (e.g. through polysemy), we assume that we account for this possible source of noise in the data by aggregating over all the concepts in a particular semantic field.
} 
Table 3 shows the semantic fields that are included in the analysis, organized along the two dimensions. ${ }^{8}$ It also specifies the number of concepts available per semantic field. The semantic field 'the human body' contains body parts and descriptions of body types, like HEAD, KNEE, FOOT and CORPULENT. The semantic field 'the house' includes concepts relating to objects and activities in and around the house, such as CUTLERY, TYPES OF POTS, CLEANING UP, WASHING and DOING DISHES. The semantic field 'celebration \& entertainment' consists of sports (and children's) games (e.g. concepts related to football, card games and to play marbles), celebrations (e.g. CARNIVAL and other calendar-bound events) and concepts relating to the arts (e.g. SCULPTOR). In the semantic field 'personality \& feelings', a few larger groups are distinguished: concepts relating to (temporary) feelings (e.g. ANGER), personality traits (e.g. TO BE SHY), types of behaviour (e.g. HASTY) and memory \& thinking (e.g. TO INFORM, TO LEARN SOMETHING). The field 'family \& sexuality' contains concepts relating to stages of life and death (and corresponding rituals), like baptism, marriage, and death and burial. The field 'society, school \& education', finally, concerns concepts relating to societal organisation (e.g. the police, war and defence), man's relation to society (e.g. language and communication), schooling and different types of transportation (e.g. by car or other types of vehicles, by train, by air).

Table 3: Semantic fields used in the study organized along the two dimensions of interest and number of concepts per semantic field in the two dictionaries

\begin{tabular}{|l|l|l|l|l|}
\hline \multirow{2}{*}{} & \multicolumn{2}{|c}{ concrete } & \multicolumn{2}{c|}{ abstract } \\
\cline { 2 - 5 } & semantic field & $\mathrm{N}$ & semantic field & $\mathrm{N}$ \\
\hline individual & the human body & 361 & personality \& feelings & 703 \\
\hline domestic & the house & 508 & family \& sexuality (WLD only) & 119 \\
\hline societal & celebration \& entertainment & 471 & society, school \& education & 974 \\
\hline
\end{tabular}

The dataset contains 3136 concepts in total. For the WLD, 1456 concepts are available, while 1680 concepts are included from the WBD. The concept-based measurements are also based on a larger number of observations in the WBD $(N=328,320)$ than in the WLD $(N=204,307)$. These differences may be related to the fact that the surface of the Brabantic dialect area is larger, contains a larger number of locations (408 versus 252 in the WLD) and has a denser distribution (i.e. the locations in the Limburgish area are, generally, geographically more distant from each other). To ensure maximal systematicity in the data, we only include data for concepts that occur in at least 50 places and data for locations with a minimum of 50 concepts available. The concept-based measurements are based on 532627 observations in total, which amounts to about 170 tokens per concept on average.

\section{Defining and operationalizing concept characteristics}

Research on prototype effects in the lexicon has shown that the semasiological structure of individual words is characterized by non-equality (e.g. cars are considered more typical types of vehicles than elevators) and non-discreteness, or fuzziness at the edges of a category (e.g. does a 'necklace' belong to

\footnotetext{
${ }^{8}$ The data for the semantic field 'family \& sexuality' from the WBD are unavailable.
} 
the category of 'clothing'?; cf. Rosch 1978 for an overview). However, similar effects can also be found at the level of the concepts within a semantic field (Geeraerts et al. 1994). In the studies by Geeraerts and Speelman mentioned above, it was shown that such concept-related prototype effects impact the amount of lexical diversity. In the following two paragraphs, these concept characteristics are defined in more detail and their operationalization is discussed. Section 3.3 elaborates in more detail on a different type of concept characteristic, viz. proneness to affect.

\subsection{Vagueness}

The notion of vagueness can be defined as fuzziness concerning the extensional boundaries of a concept belonging to a particular semantic field. For example, in the semantic field 'behaviour', it is difficult to determine where a concept like TO CRY ends, and where associated concepts, like TO WEEP or TO WHINE, begin. In the field 'artefacts', vagueness occurs between concepts like CUP and BOWL (cf. Labov 1973). One way of empirically determining whether a concept is vague is to take into account the semasiological range of the words used for the concept (see Geeraerts et al. 1994: 122-140). For instance, the concept DRENZEN 'to whine' occurs in the WBD with lexical items like jengelen, simmen and janken. The vagueness of the concept is reflected by the fact that all of these lexical variants are also used for associated concepts like AANHOUDEND KLAGEN 'to complain constantly', JANKEN 'to whine, to be in tears' and HUILEN 'to cry'. A higher degree of vagueness is expected to correlate positively with the amount of lexical diversity a concept shows, because, for vague concepts, the chance that dialect speakers from different locations all make the same demarcation choice is smaller.

The operationalization of vagueness that we use, lexical non-uniqueness, was also used in the previous studies by Geeraerts and Speelman. This measure calculates, for each concept, how often a lexical item belonging to the target concept also occurs in the database to refer to other concepts. If, for instance, a single lexical item of the target concept occurs for two alternative concepts, the measure takes a value of 2. To reduce the chance that a lexical item used for more than one concept is actually polysemous ${ }^{9}$, we calculate non-uniqueness per semantic field. The variable ranges from 0 to 257, with mean 16.76 and standard deviation 25.15. Concepts with a high degree of lexical non-uniqueness are, in the WBD, EZELACHTIG PERSOON 'a Simple Simon' (257), and, in the WLD, DEUGNIET 'rascal' (127). Concepts with a value of zero include VLIEGTUIG 'airplane' in the WBD and ZENUW 'nerve' in the WLD.

\subsection{Lack of salience}

We define salience as the degree to which a concept is experientially familiar for a language user. This perspective on salience as a cognitive phenomenon may be usefully compared to two related notions that play a role in CL. First, Langacker (1987: 59) defines entrenchment as the extent to which a linguistic structure (like a lexical item or a construction) is cognitively wired in as a result of repeated usage. Contrasting with Langacker's notion of entrenchment, we do not focus on the cognitive status of individual linguistic entities, but on the cognitive preponderance of concepts as potentially corresponding to a number of synonymous expressions. (What we are interested in overall is the way in

\footnotetext{
${ }^{9}$ Lexical items used for more than one concept can also be polysemous, rather than vague. In this case, the concepts to which the items refer are clearly distinct and not vague towards each other.
} 
which the cognitive weight of the concept influences the diversity among the various expressions.) This means, second, that our notion of salience is similar to the onomasiological salience first described in Geeraerts et al. (1994), which also involves concepts as represented by sets of synonyms rather than by individual expressions. More specifically, onomasiological salience measures the likelihood that a concept, in any of its linguistic realizations, will be used to talk about the referential phenomena within its scope. This is presented by Geeraerts and colleagues as a generalization of the basic-level hypothesis (Berlin 1978, Berlin et al. 1973): whereas the latter states that one level is the preferred one among the alternative levels of a taxonomy, onomasiological salience embodies the recognition that such differences may also occur between categories on the same level of a taxonomical hierarchy. In their study of clothing terms, for instance, they show that the likelihood that a pair of leggings will be identified as, precisely, a pair of leggings is much lower than the likelihood that a pair of jeans is identified as such, in spite of the fact that both are on the same taxonomical level, that of trousers (Geeraerts et al. 1994: 152-153). Onomasiological salience, in other words, involves a form of construal: the propensity for categorizing given phenomena with a specific concept rather than with an alternative one that could also apply (see Geeraerts 2017 for further discussion). However, because the proper operationalization of onomasiological salience requires independent evidence about the frequency of the phenomena to be categorized, it cannot be applied in a straightforward way to the data at our disposal. The notion of salience developed in the following pages, then, tries to capture familiarity with a concept as resulting from both the frequency with which language users come into contact with a particular phenomenon and the frequency with which they categorize it in a specific way, but without disentangling these two dimensions.

In practice, we rely on several measures to gauge the degree to which a concept is salient. The first two were also used in the earlier studies by Geeraerts and Speelman. The latter two serve as alternative ways to measure the degree of salience of a concept. We expect that "if a concept is less common, it is communicatively less prominent, and the possibility (or perhaps also the necessity) for standardization is more restricted" (Geeraerts and Speelman 2010: 27). Consequently, the hypothesis we aim to test with these measures is that less salient concepts (i.e. concepts with a high value for lack of salience) show a higher amount of lexical diversity (also see Szelid and Geeraerts 2008).

First, we rely on the relative number of multi-word expressions (MWEs) that occur per concept as a measure of lack of salience. The rationale for using this operationalization is two-fold. First, it relates to the predictions regarding the formal properties of names for basic level concepts. These concepts tend to be named with simplex forms, while less salient concepts are often referred to with more complex lexical items (cf. Berlin 1978, Geeraerts et al. 1994: 178-187). A second reason is that the datasets also contain hesitant, periphrastic expressions that seem to have been elicited because the respondents were not familiar with either the concept itself or with the dialect name for the concept. Such periphrastic responses can, for example, be found in the database of the WBD for the concept ONRUSTIG PERSOON 'restless person, a fidget'. About half of the observations for this concept, are a one-word lexical item, like ongedurige, woelewater or zenuwpil. The other half of the tokens, however, consist of periphrastic constructions, like levendige kwiek 'lively chap', onrustige mieter 'restless character', or je kan een ei in zijn kont gaar koken 'you can cook an egg in his bottom'. 
We operationalize the proportion of multi-word responses per concept by dividing the total number of multi-word tokens ${ }^{10}$ that occur per concept by the total number of observations. The variable ranges from 0 to 1, with mean 0.124 and standard deviation 0.223 . We expect a positive correlation between this variable and the dependent variable, lexical diversity. Concepts with a value of 1 for this variable are TER BEGRAFENIS GAAN 'to go to a funeral' in the WLD and MEINEED PLEGEN 'to commit perjury' in the WBD. Concepts with a value of 0 include AUTO 'car' in the WLD and KNIE 'knee' in the WBD.

The second operationalization of lack of salience takes into account the proportion of missing places, i.e. the proportion of locations for which no responses were provided for the concept. The assumption is that for less familiar concepts, more respondents either did not know the concept or the dialectal name for the concept, which results in a larger proportion of missing locations. However, the interpretation of this variable is ambiguous, because a higher number of missing locations can also cause a smaller amount of lexical variation, as fewer data are available for the concept. The latter effect was found for this variable in the previous studies by Geeraerts and Speelman: number of missing places showed a positive correlation with the amount of variation per concept and the validity of the measure was already problematized.

This variable is calculated as follows. First, we obtain, for each semantic field in each dictionary, the total number of locations that are available. Then, we subtract the amount of locations with data per concept from this number. Finally, the resulting figure is again divided by the total number of locations per semantic field per dictionary. The variable ranges from 0 to 0.863 with mean 0.457 and standard deviation 0.205. Concepts with a high proportion of missing places are ROOS VAN DE SCHIETSCHIJF 'bull's eye' (0.803) and WINKEL DRIJVEN 'to run a shop' in the WBD (0.863).

The first alternative measure of lack of salience is the proportion of hapax legomena per concept, i.e. the proportion of word types that occur only once for a particular concept. By using the proportion of hapaxes per concept, we take into account the fact that if a particular lexical item occurs only once for a particular concept in an entire dialect area, the chance that the dialect speaker made up this response on-the-spot is higher. ${ }^{11}$ As explained above, these types of hesitant expressions sometimes occur in the database when the dialect speaker does not know or cannot recall the name for the concept that is elicited, or when (s)he is unfamiliar with the concept itself. Consequently, the higher the proportion of hapax legomena for a particular concept, the higher the chance that the concept is less salient.

The proportion of hapaxes per concept is calculated by dividing the total number of lexical items that occur only once for a concept by the total number of tokens for the concept. It ranges from 0 to 0.794 , with mean 0.088 and standard deviation 0.089 . Concepts with a high proportion of hapaxes are VERSCHILLENDE KNIKKERSPELEN 'various games of marbles' in the WLD (0.794) and GELUIDLOOS EEN WIND LATEN

\footnotetext{
${ }^{10}$ In this paper, the words 'token', 'observation' and 'response' are used interchangeably. They all refer to a single response of a particular respondent in a particular location to a specific question.

${ }^{11}$ Note that the lexicographers of the WBD and WLD did re-elicit data if unclear responses only occurred once in a geographical region.
} 
'to let off a fart silently' in the WBD (0.635). Concepts without any hapaxes include FAKKEL 'torch' in the WLD and EETLEPEL 'spoon' in the WBD.

The second alternative operationalization of the degree of salience of a concept is based on the prevalence value of the name that is used in the dictionary to describe the concept. The prevalence data that are used were collected by Keuleers et al. (2015) in a large-scale online lexical decision experiment completed by over 365,000 participants from Belgium and the Netherlands. In this study, word prevalence is defined as "the proportion of a population knowing a particular word" (ibid.: 5). We automatically link the prevalence data, collected at the word-level, to the names for the concepts as they are available in the two dictionaries, under the assumption that the higher the prevalence value of a concept name, the more salient the concept is. The concept names that occur in the prevalence data all have a high prevalence value (the minimum z-score ranges from -1.243 to 1.960 with mean $=1.603$ and $s d=0.466$ ). However, for only $42.2 \%$ percent of the concepts from the dictionaries (1813 out of 3136 concepts), a prevalence value is available. On the one hand, this may have to do with the fact that the words that were used in the prevalence study are obtained from dictionaries and large-scale corpora. Consequently, although many words with very low frequencies are included in the prevalence study (ibid.: 4), they are probably frequent enough to occur in linguistic corpus data. This is not always the case for the data in the dictionaries, as some of the concepts have become almost obsolete (e.g. WAMBUIS 'jerkin') or are limited to very colloquial speech (like specific types of children's games, e.g. BIKKELEN 'to play knucklebones'). On the other hand, many of the concepts that are not found in the prevalence data (viz. 61.9\%), are listed in the dictionaries in the form of a multi-word expression (e.g. MUIS VAN DE HAND 'ball of the hand', PRATEN, KLETSEN 'to talk, to chatter'). Since multi-word expressions are not included in the prevalence study, these concepts are not automatically found. However, according to basic-level theory, the fact that they are listed in a multi-word form already indicates that many of them, like MUIS VAN DE HAND, are less salient as well.

Consequently, to obtain a prevalence value for all the concepts in the dictionaries, instead of just for the ones that are automatically found in the data from Keuleers and colleagues, we use a binary operationalization of prevalence in the analysis. In practice, this variable measures whether we are certain that a concept is prevalent. ${ }^{12}$ The concepts for which the mean of the standardized z-scores for Belgium and the Netherlands is higher than 0.85 (this corresponds to $80.2 \%$ of the population in Belgium and the Netherlands, on average, knowing the concept name) are categorized as 'prevalent' ( $N=1714)$. Concepts with the mean of the standardized prevalence scores equal to or smaller than $0.85(\mathrm{~N}=99)$ and concepts that are not available in the prevalence data $(N=1323)$, are categorized as 'missing/not prevalent' ( $N=1422$ ). Prevalent concepts include, in the WLD, OPSCHEPPEN 'to brag' and, in the WBD, HEMEL 'heaven'. Missing/not prevalent concepts are UNSTER 'weighbeam' in the WLD and TIEND 'tithe' in the WBD.

\footnotetext{
${ }^{12}$ The prevalence data are available separately for Belgium and the Netherlands. We rely on the mean z-score for prevalence in Belgium and the Netherlands to calculate the binary predictor variable.
} 


\subsection{Affect}

While the proneness to affect of a concept is not directly related to a prototype-theoretical view of the lexicon, it is congruent with the maximalist perspective of meaning and the encyclopaedic view on category structure of CL. In contrast to most of the measures for vagueness and lack of salience, affect is measured using information external to the dictionaries. More specifically, we rely on a forced-choice task to collect affect ratings for the entire datasets.

The raters received a tabular file containing the names of the concepts that occur in the data, organized per semantic field. Before distributing the file, we linked the concepts in the WBD to the concepts in the WLD to ensure that identical concepts receive the same affect rating. In total, the file contains 1935 concepts. The file also provides information about the subsection in the dictionaries to which the concept belongs, which indicates how it can be interpreted (e.g. ONNOZELE-KINDERENDAG 'Holy Innocents' Day' is listed under calendar-bound practices, which is subsumed under festivities and practices in the semantic field 'celebration \& entertainment'), and a definition of the concept. The raters also received a document with instructions. They were asked to use their best judgement in deciding whether a certain concept has a connotation. They could choose between four values: negative connotation, positive connotation, neutral concept or uncertain. ${ }^{13}$ Five raters coded the concepts in the database for affect, but only three of them completed the ratings for every semantic field. Four raters were early-stage researchers at the Department of Linguistics of the KU Leuven. One participant was an older, highly educated female, external to the department. ${ }^{14}$

The Light's kappa value of 0.675 , an adjusted version of Cohen's kappa for more than two coders (Hallgren 2012, Levshina 2015), indicates a moderate to substantial amount of agreement between the raters. ${ }^{15}$ Disagreement mostly stems from their individual cut-off points of non-neutrality, rather than from contradictory choices regarding the positive or negative valence of a concept. For example, for the concept DIABOLO 'diabolo', three raters indicate that the concept is neutral, while two raters code it as positive; the concept LIJKWAGEN 'hearse' is rated as negative by four coders and as neutral by the fifth

\footnotetext{
${ }^{13}$ We consciously refrained from using a numerical scale in the experiment, because preliminary analyses indicated that positive and negative concepts, which would be on opposite ends of such a scale, show similar amounts of lexical diversity. The distinction between neutral and non-neutral concepts, however, was much more apparent. ${ }^{14}$ Because the number of raters that participated in the experiment was somewhat low, we verified the validity of the ratings. Examining the degree to which they correlate with the 691 concepts for which mean valence information is available from data collected on a much larger scale by Moors et al. (2013) indicates that the ratings provided by our respondents are reliable.

${ }^{15}$ Light's kappa was calculated on the full dataset by only using the ratings from the three coders who completed ratings for all six semantic fields. Additionally, we calculated Light's Kappa per semantic field to also compare the validity of the measure for the raters who only coded a subset of the semantic fields. The analysis indicates that Light's Kappa differs between semantic fields: it takes values between 0.326 and 0.746 . Low kappa values are found for the semantic fields of celebration \& entertainment (0.326) and family \& sexuality (0.349), two fields that contain a relatively large amount of obsolete concepts (e.g. highly specialized concepts relating to pigeon keeping and concepts like AARDAPPELFOOI 'festivities held after harvesting the potatoes (lit.: potato reward)', BRUIDSJONKER 'page (at a wedding)', DOOPMUTSJE 'bonnet worn during a baptism', HOGE HOED BIJ BEGRAFENIS 'top hat worn at a funeral'), while high values occur for fields with more universal or modern concepts (personality \& feelings: 0.746, society, school \& education: 0.667). Furthermore, the differences are again predominantly related to the raters' individual cut-off points of non-neutrality, especially for concepts that are less well known in modern-day life.
} 
one. For only 59 concepts out of the 1935 , contradictory choices between the positive and negative valence of the concept occur. Consequently, we operationalize affect as a measure of certainty regarding the non-neutrality of a particular concept. More specifically, it is calculated as the proportion of nonneutral ratings per concept. For instance, for the concept BARENSWEEËN 'labour pains', five rating scores are available, with four of these indicating that the concept is non-neutral (viz. negative). The value for affect-sensitivity is, thus, 0.8 . If the ratings are categorized as neutral versus not-neutral (i.e. positive or negative) in this way, Light's kappa is equal to 0.645 .

The proportion of non-neutral ratings per concept ranges from 0 to 1 , with mean 0.427 and standard deviation also 0.427 . Concepts with a value of 1 for proportion of non-neutral ratings include LIEFKOZEN 'to caress' and OPSCHEPPERIJ 'bragging'. A value of 0 is found for concepts like KINDERSTOEL 'baby chair' and MIAUWEN 'to miaow'.

\section{Dependent variable}

The dependent variable used in the analysis, lexical diversity per concept, is operationalized in the same way as in the studies by Geeraerts and Speelman to ensure that the results are comparable. This variable is a composite variable that takes into account several aspects of lexical diversity in the dialect lexicon. The calculation of the variable consists of several steps.

First, the variable considers the number of different types per concept. This variable ranges from 1 to 202 with mean 23.3 and standard deviation 20.588. Concepts with a high value for this variable are RIJK ZIJN 'to be rich' (WLD: 202 types; WBD: 191 types) and AARZELEN, TREUZELAAR 'to hesitate, dawdler' in the WBD (194 types). Only one lexical item is used for concepts like ORGEL 'pipe organ' in the WLD and TEEN 'toe' in the WBD. Alternative operationalizations of this measure can be envisaged that take into account the number of tokens per concept and the frequency distribution of the available lexical items (for examples, see Cornips et al. 2016, Geeraerts et al. 1999 and Swanenberg 2004, 2010). However, because we aim to keep the analysis comparable to the earlier studies, we rely on the calculation used in these studies.

Second, the operationalization of the dependent variable also reflects the fact that dialectal data are geographically stratified. Following the earlier studies by Geeraerts and Speelman, the operationalization of the degree of geographical fragmentation a concept shows, takes into account the average geographical distance between two locations with the same variant (dispersion) and the average geographical surface of a particular lexical item (range) per concept. Conceptually, the degree to which a particular concept shows dispersion concerns the degree to which, on average, the geographical distribution of the lexical variants for the concept is characterized by the interference of other lexemes that are used for the same concept. A concept is highly dispersed if the lexical variants are scattered across geographical space in a heterogeneous way, without the formation of clear areas where a particular variant is used consistently, but rather with several variants used intermittently (Figure 1). Little dispersion occurs if homogeneous areas can be distinguished, as in Figure 2. Dispersion per concept is calculated by relying on the average degree of dispersion of all the lexical items for the concept. First, for every location where a particular variant occurs, the distance (in terms of geographical distances) to 
the nearest location with the same variant for the same concept, is measured. Then, the average of these distances to the nearest location with the same word is calculated for all the locations where the lexical item under scrutiny occurs. Second, again for every location where the variant is found, the distance to the nearest location with any observation for the concept is taken into account. Again, the average of this measure is calculated as well. The dispersion of the lexical variant is then quantified by dividing the first averaged figure (average distance to the nearest location with the same term) by the second one (average distance to the nearest location with any observation for the concept). The dispersion of a concept is subsequently calculated as the average amount of dispersion for all the lexical items that occur for the concept. This average is also weighted by the relative contribution of each lexical item to the onomasiological profile of the concept. ${ }^{16}$ Dispersion ranges from 1 to 4.401 , with mean 1.894 and standard deviation $0.590 .{ }^{17}$ Concepts with a high degree of dispersion include VERBEUZELEN 'to squander' in the WLD (4.401) and IEMAND WEERSTAAN 'to resist someone' in the WBD (4.323; Figure 1). Concepts like JoJo 'yo-yo' in the WLD and GETUIGE 'witness' in the WBD, have a value of 1 for dispersion. Figure 2 shows the distribution of the variants for the concept sLUIS 'lock (in shipping)' in the WBD, which also has a low value for dispersion (1.120).

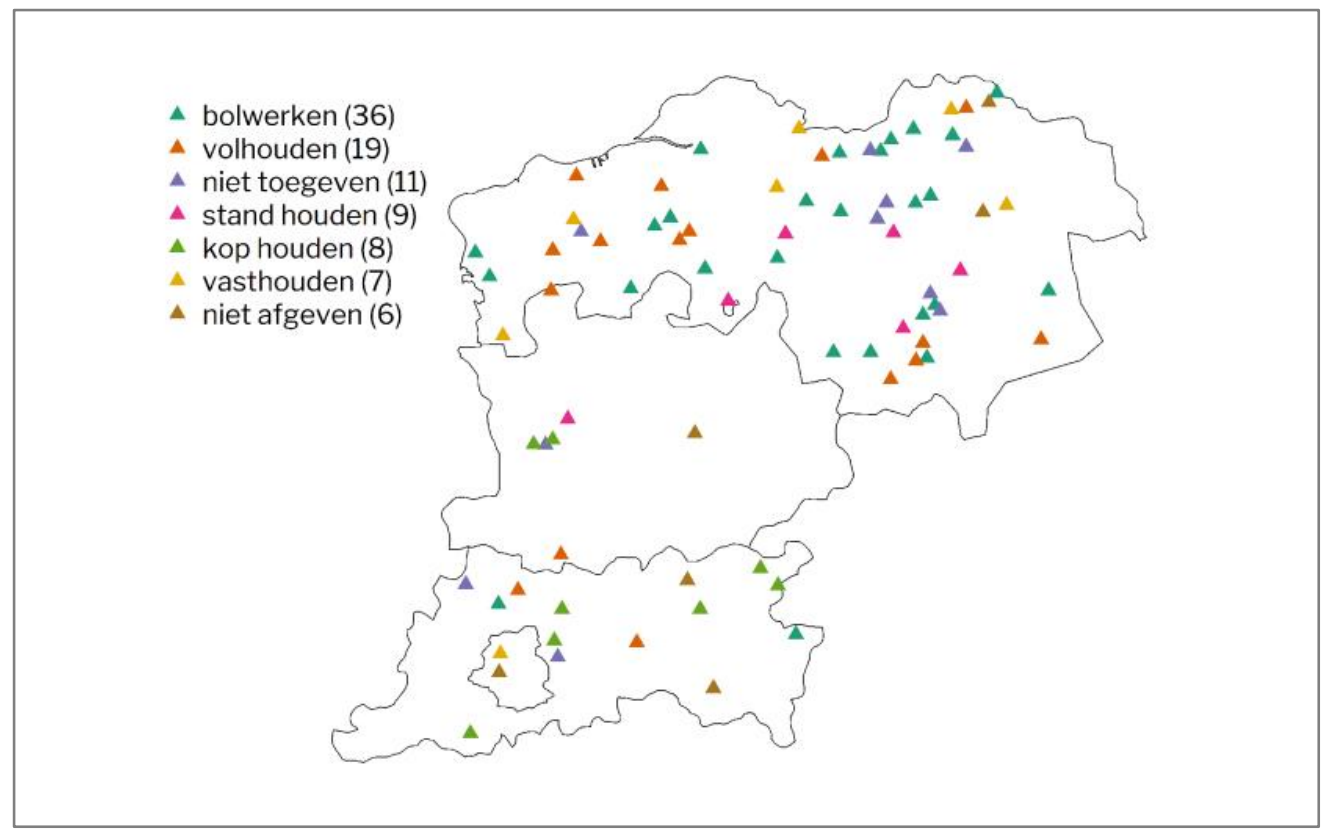

Figure 1: Geographical distribution of the lexical variants for IEMAND WEERSTAAN 'to resist someone' in Brabant (only items that occur more than 5 times in the WBD are included)

\footnotetext{
${ }^{16}$ An onomasiological profile takes into account the relative frequency of each lexical item used for a particular concept (Speelman et al. 2003). For instance, if for a particular concept Z, three lexical items occur with differing frequencies ( $a$ : 10 observations, $b$ : 60 observations and $c$ : 30 observations), the relative contribution of each variant is calculated as the number of observations per variant divided by the total number of observations for the concept. For variant $a$, the relative contribution is, thus, 0.1 ; for $b$, it is 0.6 and for $c$ it is equal to 0.3 .

17 The geographical distances and areas are not expressed in (squared) kilometres. We use a different coordinate reference system available in the geolocation data of the WBD and WLD than longitude and latitude.
} 


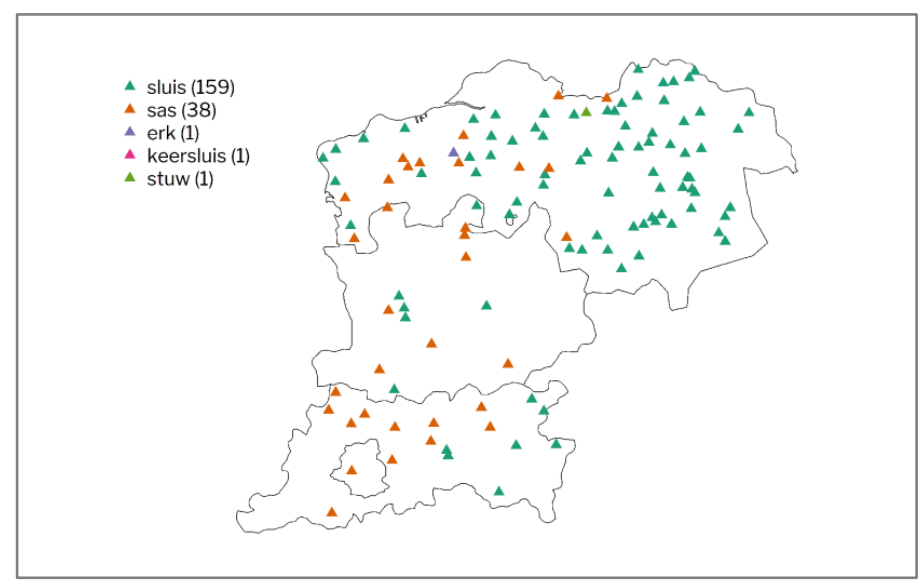

Figure 2: Geographical distribution of the lexical variants for sLUIS 'lock (in shipping)' in Brabant

Next to dispersion, geographical fragmentation is also influenced by the range of occurrence of a concept: the data for concepts for which the average range of the lexical variants is high, like in Figure 2, are less fragmented than for concepts with a smaller geographical range. An example of a concept of the latter type is provided in Figure 3. Only lexical items that occur more than three times for this concept are plotted with a coloured triangular symbol. Other locations where data for the concept occur, are indicated with a grey circle.

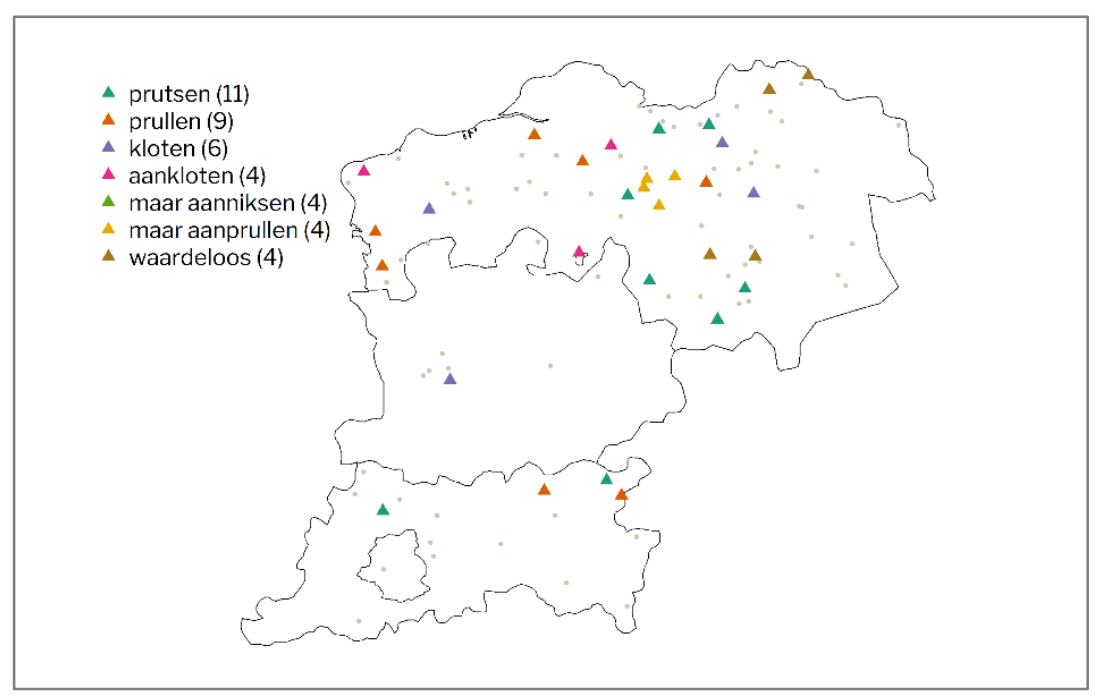

Figure 3: Geographical distribution of the lexical variants for NUTTELOZE ARBEID VERRICHTEN; NUTTELOOS WERK 'to mess about' in Brabant. Only items that occur more than 3 times in the WBD are plotted. To show the total range of the concept, other locations for which data are available, are indicated with a grey circle

To calculate the geographical range of a concept, we rely on the relationship between, on the one hand, the average geographical area spanned by each lexical item for the concept and, on the other hand, the total area where the concept occurs. Most concepts in the datasets occur in the entire Limburgish or 
Brabantic dialect area. First, for each lexical item per concept, the area where the word occurs is measured to obtain the range per lexical item. This area is subsequently divided, per lexical item, by the total area where the concept occurs. The geographical range for a specific concept then consists of the average of the range for all the lexemes used for the concept. For this variable, the importance of each lexical item for the aggregated variable is weighted in function of its relative contribution to the onomasiological profile as well. Geographical range per concept takes values between 0.003 and 1 in the datasets, with mean 0.579 and standard deviation 0.229 . Concepts with a low value for range include VERSCHILLENDE KNIKKERSPELEN in the WLD (0.003), a concept for which respondents were asked to provide names for different games of marbles that they are familiar with, and NUTTELOZE ARBEID VERRICHTEN; NUTTELOOS WERK 'to mess about' in the WBD (0.076; Figure 3). A value of 1 for range is found for concepts like LUISTEREN 'to listen' in the WLD and GETUIGE 'witness' in the WBD. An example of a concept with a value for range that is only slightly lower than 1, is found in Figure 2: SLUIS 'lock (in shipping)' has both a low value for dispersion and a relatively high value for weighted averaged range (0.879).

The composite variable, lexical diversity, is calculated by using the following formula ${ }^{18}$ :

$$
\text { lexical diversity }=\text { number of unique types } * \frac{\text { dispersion }}{\text { range }}
$$

In practice, we use the natural logarithm of lexical diversity, because the dependent variable is right skewed. Using the logarithm of this variable also results in a more linear relationship between the predictor variables and the response. The logarithm of lexical diversity ranges from 0 to 9.560 with mean 4.054 and standard deviation 1.507. Concepts with a high value for the dependent variable are VERSCHILLENDE KNIKKERSPELEN 'various games of marbles' (9.513) in the WLD and GELUIDLOOS EEN WIND LATEN 'to let off a fart silently' (8.652) in the WBD. A concept with a value equal to zero (i.e. concepts with one lexical item that occurs everywhere) is BLOED 'blood' in both dictionaries.

\section{Results}

The impact of the predictors on the dependent variable is assessed using linear regression analysis. From a theoretical perspective, it is necessary to explore interaction effects between all the predictors. On the one hand, to examine whether the results of the previous studies are generalizable and whether the effect of the concept characteristics is equally strong across dialect regions and semantic fields, we

\footnotetext{
${ }^{18}$ Using the product of number of unique types and geographical fragmentation has as a benefit that it reduces possible circularity in the data which may arise when both the response and predictor variables are based on the distribution of lexical items. For most predictors, circularity is not a problem as their calculation relies on other features of the data, such as the distribution of lexical items for other concepts than the target concept (lexical non-uniqueness), on formal properties of the lexical items (proportion of multi-word units), or on data external to the dictionaries (e.g. proportion of non-neutral ratings). However, using the proportion of hapaxes per concept may be problematic as the number of unique types is per definition larger for concepts with a larger proportion of hapaxes. Using the product of number of unique types and geographical fragmentation reduces this direct correlation as geographical fragmentation takes into account the onomasiological profile of the concept: it attaches more importance to lexical items that occur frequently and very little weight to lexical items that occur only once. Furthermore, in a regression model that does not include the proportion of hapaxes as a predictor, the effect of lack of salience (and of the other variables) remains significant and stable.
} 
analyse interactions between the dictionary of the concept and all the concept characteristics, and between semantic field and all the concept characteristics. On the other hand, we also want to take into account interactions between the concept characteristics. Thus, as the model is relatively complex, we rely on a semi-automatic model selection procedure that consists of several steps. ${ }^{19}$

First, we rely on an automatic backward selection algorithm that uses the AIC criterion of the models and that allows for two-way interactions between all the predictors in the model. We subsequently exclude model terms and interactions that do not significantly contribute to the explanatory power of the model. Additionally, we remove interactions between single predictors that model the same overarching variable to avoid a harmful amount of multicollinearity in the model. For instance, we do not allow for an interaction between proportion of multi-word expressions per concept and proportion of hapaxes per concept, as both of these variables model the influence of lack of salience. Finally, we avoid overfitting by only retaining the interactions that contribute enough to the reduction of the variation in the response variable.

Before interpreting the results of the model, the assumptions were examined. More specifically, we verified that the relationship between the predictors and the dependent variable is linear, that there are no outliers, that the model does not suffer from heteroscedacity, that there is no harmful multicollinearity between the predictors and that the residuals are normally distributed. The model suffers from some heteroscedacity (due to the fact that the data only contain a few observations with a very high value for the dependent variable) and the relationship between the dependent and some explanatory variables is only linear-like. However, as the results are stable under bootstrapping, using the procedure outlined in Levshina (2015: 167-169), the predictors in the model are robust.

The output of the regression model is shown in Table 4. All the fixed-effects predictors that were discussed above, reach significance. The adjusted $R^{2}$ value of the model is 0.7311 , which indicates that about $73 \%$ of the variance in the response variable is explained by the combination of the predictors and interaction effects.

\footnotetext{
${ }^{19} \mathrm{~A}$ reviewer correctly points out that following an automatic selection algorithm is generally dispreferred over a theoretically informed manual model selection method. However, we have verified that a manual selection procedure, broadly following Zuur et al. (2009: 121-122), produces the same results.
} 
Table 4: Output of the regression model

\begin{tabular}{|c|c|c|c|}
\hline model term & estimate & SE & p-value \\
\hline Intercept & 2.586 & 0.072 & $<0.001$ \\
\hline \multicolumn{4}{|l|}{ Dictionary } \\
\hline WBD & 0.184 & 0.032 & $<0.001$ \\
\hline \multicolumn{4}{|l|}{ Semantic field } \\
\hline the house & 0.344 & 0.082 & $<0.001$ \\
\hline celebration \& entertainment & 0.059 & 0.079 & NS \\
\hline personality \& feelings & 0.200 & 0.090 & $<0.05$ \\
\hline family \& sexuality & 0.132 & 0.121 & NS \\
\hline society, school \& education & 0.274 & 0.072 & $<0.001$ \\
\hline \multicolumn{4}{|l|}{ Lack of salience } \\
\hline proportion of missing places & -1.055 & 0.104 & $<0.001$ \\
\hline proportion of MWEs & 0.583 & 0.076 & $<0.001$ \\
\hline proportion of hapaxes & 13.318 & 0.552 & $<0.001$ \\
\hline prevalence binary (missing / not prevalent) & 0.228 & 0.032 & $<0.001$ \\
\hline \multicolumn{4}{|l|}{ Vagueness } \\
\hline lexical non-uniqueness & 0.032 & 0.003 & $<0.001$ \\
\hline \multicolumn{4}{|l|}{ Affect } \\
\hline proportion of non-neutral ratings & 0.280 & 0.042 & $<0.001$ \\
\hline \multicolumn{4}{|l|}{ Interaction terms } \\
\hline sem. field (the house) : proportion of hapaxes & 1.483 & 0.792 & $<0.1$ \\
\hline sem. field (celebration \& entertainment) : proportion of hapaxes & -3.220 & 0.638 & $<0.001$ \\
\hline sem. field (personality \& feelings) : proportion of hapaxes & -1.867 & 0.626 & $<0.01$ \\
\hline sem. field (family \& sexuality) : proportion of hapaxes & 0.736 & 1.205 & NS \\
\hline sem. field (society, school \& education) : proportion of hapaxes & -1.195 & 0.639 & $<0.1$ \\
\hline sem. field (the house) : lexical non-uniqueness & -0.002 & 0.004 & NS \\
\hline sem. field (celebration \& entertainment) : lexical non-uniqueness & 0.018 & 0.006 & $<0.01$ \\
\hline sem. field (personality \& feelings) : lexical non-uniqueness & -0.012 & 0.003 & $<0.001$ \\
\hline sem. field (family \& sexuality) : lexical non-uniqueness & -0.007 & 0.010 & NS \\
\hline sem. field (society, school \& education) : lexical non-uniqueness & 0.001 & 0.003 & NS \\
\hline proportion of hapaxes : lexical non-uniqueness & -0.065 & 0.007 & $<0.001$ \\
\hline
\end{tabular}

To interpret the partial contribution of each predictor to the explanatory power of the model, we start with the variables that are not included in any interaction effect. The results for the variables that are included in an interaction will be inspected visually below. Overall, the model confirms the results obtained in the previous studies: more variation is found for vaguer and less salient concepts and for 
concepts that are prone to affect. Additionally, we find that some concept characteristics have a larger effect size in some semantic fields than in others, which exemplifies that taking more than one semantic domain into account is necessary.

\subsection{Main effects}

The first variable that is not included in an interaction effect is the dictionary to which the concept belongs. The reference level for this variable, WLD, is included in the intercept. To determine the effect of the variable, we compare the estimate (in the second column of the table) and the $p$-value (in the last column) for the alternative level, WBD, to the intercept. Because the p-value for the alternative level is smaller than the alpha level, 0.05 , we can infer that the amount of lexical diversity differs significantly between the dictionaries, if all the other variables are taken into account. The direction of this effect is reflected by the estimate (0.184). The positive sign reveals that significantly more variation is found in the Brabantic data. This is an interesting finding as the Brabantic dialect area is more urbanized than the Limburgish one, which is generally assumed to result in dialect levelling and, thus, in a decrease in the amount of variation (e.g. Milroy 2002, Trudgill 2011). Perhaps this finding is related to the data itself: the Brabantic dialect area has a larger surface and more data from the WBD are available. As a result, the chance of finding a larger number of variants per concept is higher. Crucially, because no significant interaction effects are found with any of the other predictor variables and 'dictionary', the model confirms that the effect of the concept characteristics is stable across the two dialect areas.

The second set of variables in the table that are not included in an interaction effect, viz. proportion of missing places, proportion of MWEs and prevalence, involve the lack of salience of a concept. The small $p$-value and the negative sign of the estimate $(-1.055)$ for the former predictor indicate that a significant negative correlation is found between the proportion of missing places for a particular concept and the amount of variation the concept shows. Although this is not the effect that we expected, as we assumed that concepts with a higher amount of missing places are less salient and, thus, predicted a positive correlation, the effect of this variable was the same in the earlier studies by Geeraerts and Speelman mentioned above. In these studies, this finding was explained by the fact that a larger amount of missing places may also result in a smaller amount of lexical variation per concept, due to the fact that less data are available.

Furthermore, for the other variables that measure the lack of salience of a concept, we do find the expected effect: less salient concepts show significantly more variation across the dictionaries and in every semantic field. First, the model finds a significant positive correlation between the proportion of MWEs per concept and the amount of lexical diversity, as indicated by the positive estimate $(0.583)$ and the small p-value. Second, the results also indicate that significantly more variation (0.274) is found for non-prevalent concepts or concepts that are not available in the prevalence data collected by Keuleers et al. (2015), in comparison to the concepts that are prevalent (the reference level, included in the intercept).

The last variable that is not included in any interactions, proportion of non-neutral ratings, measures the affect sensitivity of a concept. The higher the proportion of non-neutral ratings for a particular concept, 
the more the concept is prone to affect. The estimate $(0.280)$ and small $p$-value for this variable indicate that the effect is as expected across dictionaries and semantic fields: significantly more variation is found for concepts that are prone to affect.

\subsection{Interaction effects}

Next, we turn to the first interaction effect included in the model, between semantic field (reference level 'the human body') and proportion of hapaxes (an operationalization of lack of salience). A visualization of the effect of this interaction is presented in Figure 4. The figure shows the predicted effect of proportion of hapaxes (in different colours) on the dependent variable, lexical diversity, on the $y$-axis, per semantic field (on the $x$-axis). The semantic fields are organized along the $x$-axis in the following way: first, the three more concrete semantic fields are shown, organized from universal (the human body) and domestic (the house) to societal (celebration \& entertainment). Then, the three more abstract fields are shown, again organized from universal (personality \& feelings), via domestic (family \& sexuality), to societal (society, school \& education). As explained above, the universal - domestic societal axis is based on the lay-out of the dictionary.

Crucially, although the interaction effect is significant, proportion of hapaxes has the same effect in every semantic field: more variation is found for concepts with a high value for this predictor (i.e. concepts that are less salient) in every semantic domain. The interaction effect merely indicates that the impact of a larger proportion of hapaxes is greater for domestic than for non-domestic semantic fields. More specifically, it has a significantly larger effect in the domestic semantic field 'the house' and a significantly smaller influence in the other universal field (personality \& feelings) and the societal semantic fields (celebration \& entertainment and society, school \& education) in comparison to the reference level. Pickl (2013) asserts that semantic fields that contain concepts that are mostly limited to domestic life are not often discussed in conversations with interlocutors from locations farther away. As a result, these fields are less prone to lexical levelling and more prone to lexical diversity. Although the semantic fields in our dataset are not completely identical to the domains used in Pickl's study, the interaction effect seems to indicate that this difference between domestic and non-locally bound fields is stronger for concepts that are not salient (i.e. with a large proportion of hapaxes). Perhaps this finding can be explained by the fact that universal or societal concepts are more salient in general, because they are communicatively relevant on a larger scale. As a result, the potential effect of the proportion of hapaxes in non-local fields may be smaller in general. 


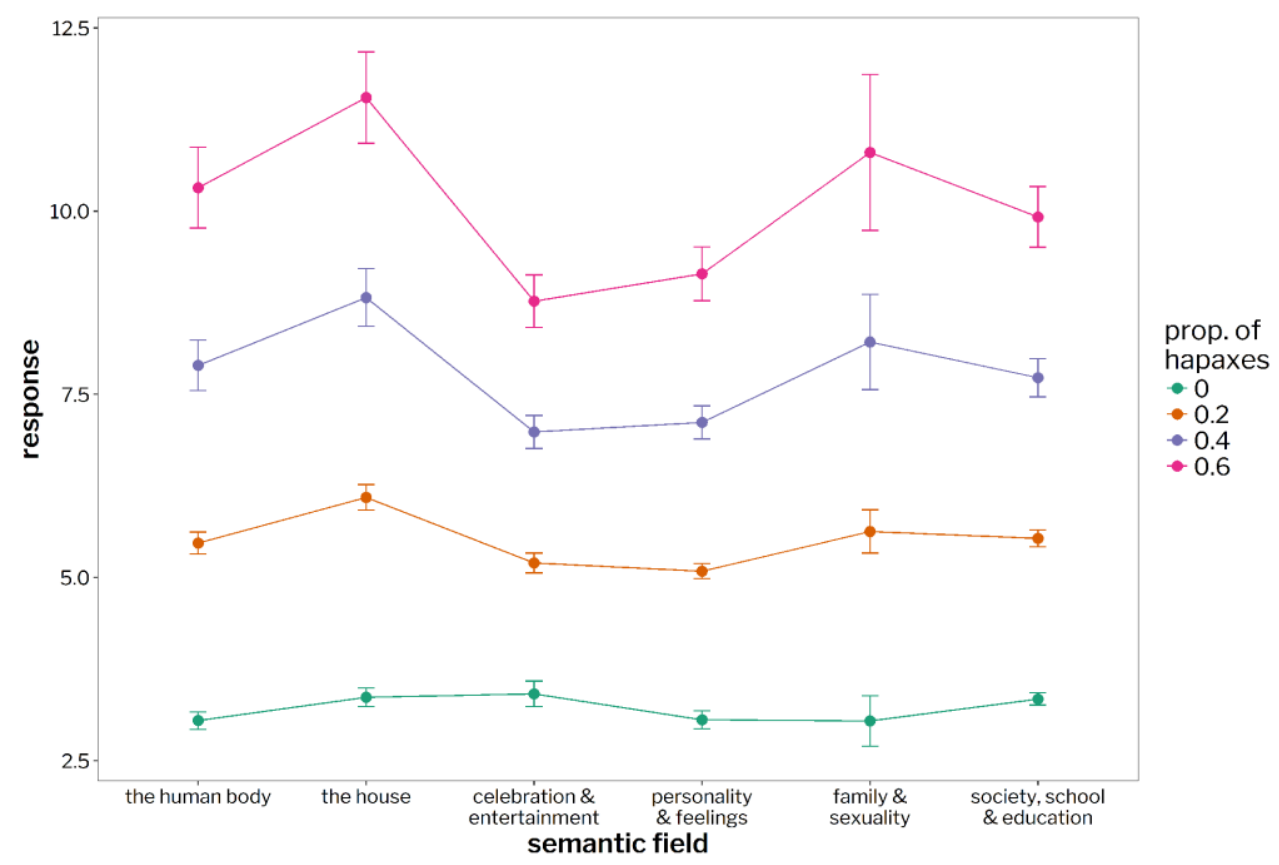

Figure 4: Interaction between semantic field and proportion of hapaxes

The second interaction effect included in the model concerns the influence of lexical non-uniqueness per semantic field (Figure 5). As explained above, lexical non-uniqueness measures how often a lexical item that occurs for the concept under scrutiny is used to refer to other concepts as well. Again, the most important finding that the interaction effect shows, is that the impact of lexical non-uniqueness is the same across semantic fields: vaguer concepts show more lexical diversity in every domain. However, the figure again indicates that differences in the strength of the variable exist between semantic fields. More specifically, the impact of lexical non-uniqueness seems to be greater for the three semantic fields with a large amount of concrete concepts on the left of the figure (the human body, the house and celebration \& entertainment) than for the three more abstract semantic fields to the right of the figure (personality and feelings, family \& sexuality and society, school \& education). This may have to do with the fact that, for concrete concepts, perceptual information is available which may make them relatively easily distinguishable from related concepts (at least towards "co-hyponymous" concepts, at the same taxonomical level). By contrast, for more abstract concepts, perceptual clues are not available, which may result in these concepts being more vague in relation to concepts on the same taxonomical level. Consequently, if abstract concepts are vaguer than concrete ones in general, this reduces the effect that lexical non-uniqueness can have on the amount of variation these concepts show. However, at this point, the degree of concreteness is measured per semantic field and by relying on concreteness ratings for words. This explanation can only be corroborated further by means of concreteness ratings per concept. 


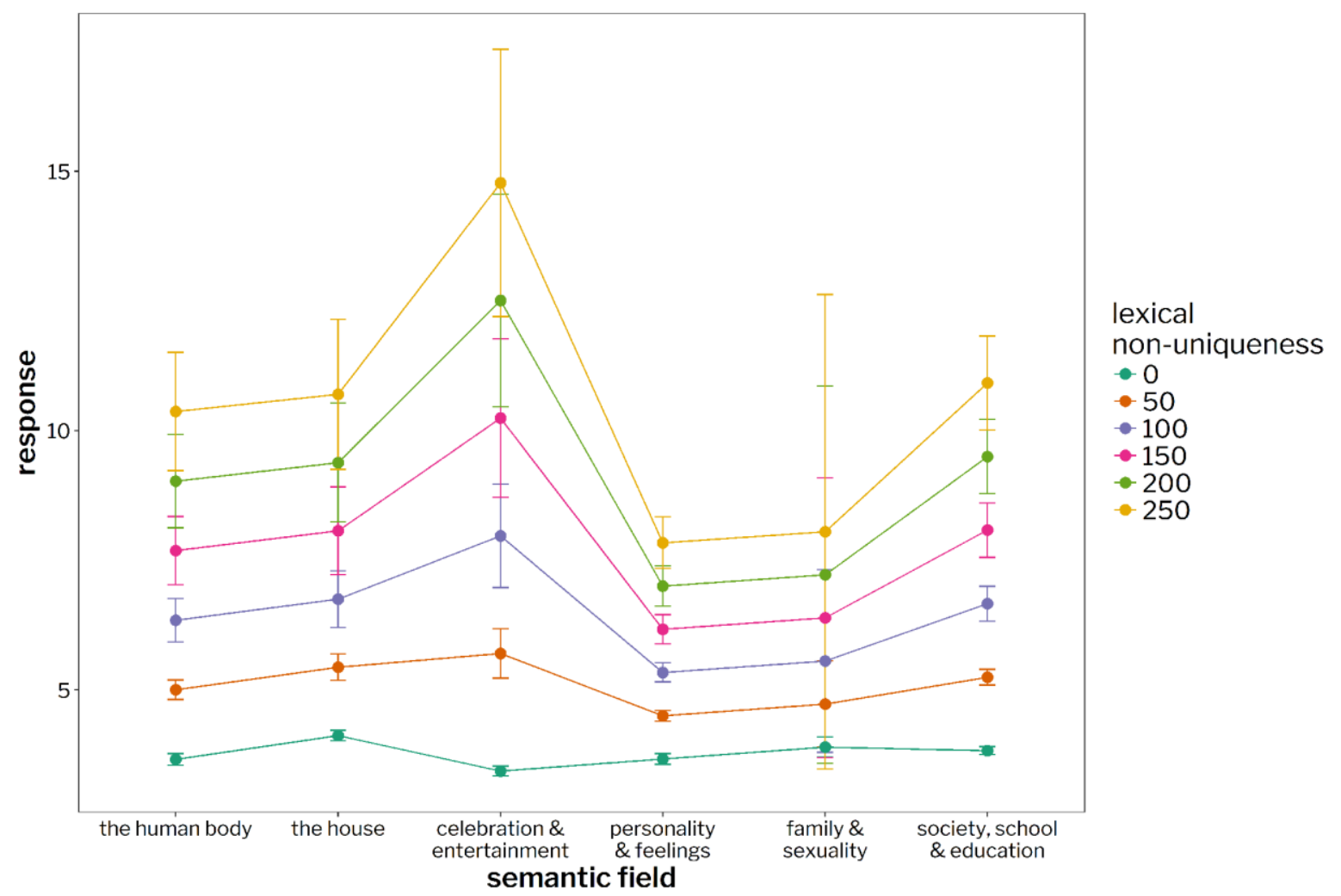

Figure 5: Interaction between semantic field and lexical non-uniqueness

Additionally, these results need to be attenuated. First, the error bars indicate that results are less reliable in every semantic field for concepts with a very high value for lexical non-uniqueness. However, the difference between the concrete and abstract semantic field remains stable and significant in a model that only includes concepts with a value lower than 50 for lexical non-uniqueness. Additionally, preliminary analyses indicated that significant differences in the amount of lexical non-uniqueness occur between the semantic fields: only a few concepts have a relatively high value for lexical non-uniqueness in the semantic fields of celebration \& entertainment (min.: 0, max.: 40, mean: 5.686, sd: 7.376) and family \& sexuality (min.: 0, max.: 35 , mean: 5.681 , sd: 8.465). Consequently, the predicted values that are shown in Figure 5 for these semantic fields are only based on observations for a limited set of concepts (as indicated by the error bars). The concepts that are the most vague in the field 'celebration \& entertainment' all relate to the same topic, viz. children's games, especially playing with marbles (e.g. STUIKEN 'to throw marbles in a pit', KNIKKER 'marble', BONKEN 'to let marbles bounce against each other'). It is not surprising that these concepts show a high amount of lexical diversity as children's games are known to be lexically diverse due to the creative nature of child language. A similar pattern shows up for the semantic field 'family \& sexuality': the concepts with the highest value for lexical non-uniqueness are also limited to specific semantic subfields. They either concern a young person (KIND (TROETELNAAM) 'kinship terms for a child', PUBER 'adolescent', MEISJE MET WIE EEN JONGEN VERKERING HEEFT 'girlfriend of a boy'), or indecency (ONKUIS 'indecent', MANZIEK 'nymphomaniacal'). 
The final interaction effect in the model concerns the relationship between lexical non-uniqueness and proportion of hapaxes. Figure 6 shows the effect of this interaction. On the x-axis, lexical non-uniqueness per concept is provided. The influence of proportion of hapaxes per concept on the dependent variable ( $y$-axis) is indicated with coloured lines (and corresponding error bars and confidence bands). The figure shows that the influence of lexical non-uniqueness is especially large for concepts that are highly salient (i.e. that occur with a low proportion of hapaxes). If these concepts are relatively vague, they show much more variation than their non-vague counterparts. However, the impact of lexical non-uniqueness decreases for less salient concepts. Because the number of concepts with very high values for lexical non-uniqueness is relatively small, the confidence bands towards the right of the figure overlap. However, the effect remains stable in a model that only includes concepts with a value smaller than 50 for lexical non-uniqueness. Additionally, most of the concepts have a relatively low proportion of hapaxes: only 184 out of the 3136 concepts in the database have a proportion of hapaxes larger than 0.25 . Consequently, for the highly non-salient concepts, the effect is only based on a small number of observations.

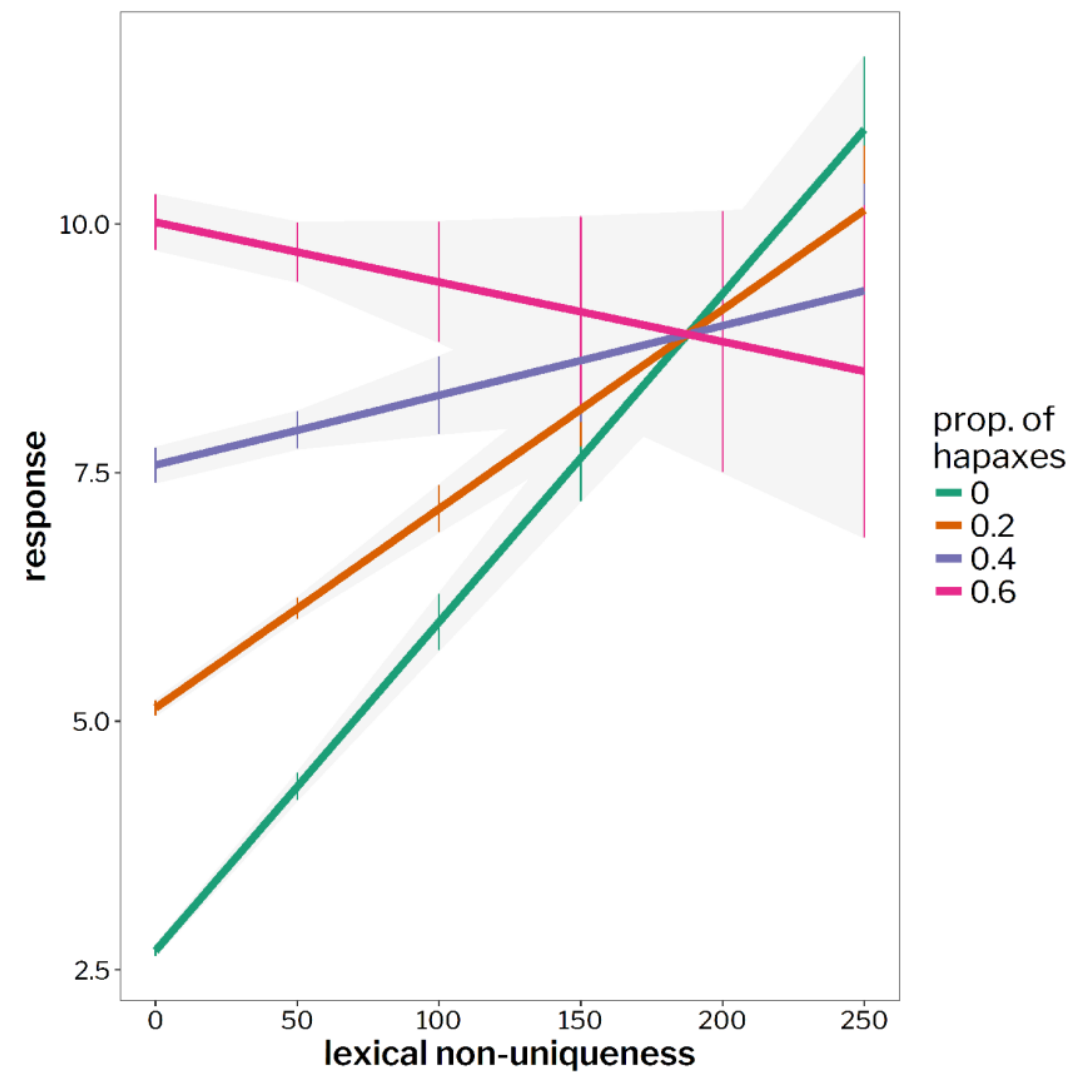

Figure 6: Interaction between lexical non-uniqueness and proportion of hapaxes

Perhaps this finding can be explained by the fact that non-salient concepts show a lot of variation overall, regardless of whether or not they are vague. For instance, for the non-salient (proportion of hapaxes $=0.567$ ), but also non-vague (lexical non-uniqueness $=4$ ) concept STAARTDUIF 'pigeon listed as one of the last winners (pigeon keeping)' in the WBD, a lot of variation still occurs. For instance, 41 lexical items exist for the concept, which show a lot of geographical fragmentation (dispersion $=2.09$, 
range $=0.13$ ). Out of these 41 lexemes, 37 do not occur for other concepts in the WBD. This indicates that many of these lexical items are used hesitantly, which results in the smaller impact of lexical nonuniqueness for less salient concepts. For more salient concepts, however, vagueness does play a larger role: the difference between non-vague and vague concepts is much larger. For non-vague salient concepts, there is generally very little variation: one or a few lexical items take up a very strong position in the profile for the concept and not many other lexical items occur. This is, for instance, the case for BLOED 'blood' (0 hapaxes, 0 lexical items that occur for other concepts as well), for which 1 variant, bloed, is used everywhere. For vaguer salient concepts, however, additional variants do occur. For example, for the salient and vague concept SLIM (ZIJN) '(to be) smart', one lexical item is relatively frequent throughout the Brabantic dialect area, viz. slim: it is used in $48.97 \%$ of all observations for the concept. Additionally, however, 69 other lexical items exist that all contribute much less to the geographical profile of the concept.

\section{Discussion}

The aim of this paper was to examine the generalizability of the effect of concept characteristics on lexical diversity, described in earlier studies by Geeraerts and Speelman, to the dialect lexicon as a whole, by not only investigating whether their impact is stable and independent from semantic field and dialect area but also whether differences that we may find are categorical or gradual. First, our results confirm that the effect of these characteristics is the same across the dialect lexicon: we find more variation for vaguer, less salient and affect-sensitive concepts in every semantic field and in both dialect areas. Crucially, the number of significant interaction effects in our regression model is limited, which demonstrates that the influence of these characteristics is direct and substantial. More specifically, the effect of the concept characteristics under scrutiny is independent of region, as we find no significant interactions between any of the predictors and the dictionary to which the concepts belong. Furthermore, the regression model did not contain any interaction effects between semantic field and affect, which indicates that the effect of this concept characteristic is fully independent of semantic field.

Second, we refined the results of the earlier studies by showing that the strength of the effect of vagueness and lack of salience is gradual depending on semantic field. Specifically, the degree of universality/domesticity of a semantic field, a sociocultural feature, and the average degree of concreteness, an experiential feature with an effect on language processing, interacts with the amount of variation that is explained by some of the concept characteristics (viz. lack of salience and vagueness). On a theoretical level, these findings open up a novel perspective for lexical semantics from a $\mathrm{CL}$ perspective. While some studies have already shown that the structure of the lexicon can differ between semantic fields, as, for instance, loanwords occur more often in specific fields (e.g. Geeraerts et al. 1999, Tadmor 2009: 64-65, Zenner et al. 2012), research that explicitly looks at the way in which diversity in the lexicon may in itself be dependent on socio-cultural, processing-related, or possibly other features of a semantic field, is still largely lacking. In this respect, our study contributes to lexicological theory formation by showing that the complex interaction between meaning, categorization and the environment of language users impacts the structure of lexical variation. More broadly, these results tie in with the conception of Cognitive Linguistics formulated most explicitly in the context of Cognitive 
Sociolinguistics: variation in language use occurs at the interface of experiential factors of a more narrowly cognitive nature and ones of a socio-cultural, contextual kind.

The methodological innovation of our study resides in the fact that, while all the analyses are completely comparable to the ones of the earlier studies, we also introduced new methods to gauge the concept characteristics. Specifically, using psychometric data as an operationalization of salience is an avenue that had not been embraced before and that may be easily employed in other research projects, given the fact that a similar psychometric dataset has recently also become available for English (Brysbaert et al. 2018). Furthermore, while the earlier studies relied on a more limited dataset and, perhaps for this reason, on a model that did not include interaction effects between the concept characteristics, we did examine this relationship. This indicated that vagueness predominantly affects less salient concepts, which already show a lot of variation in general. Finally, our use of a larger dataset indicated that there is significantly more lexical diversity in the Brabantic dialect region than in the Limburgish one. As the Brabantic region is more urbanized than the Limburgish one, this contrasts with what would be expected on the basis of research into lexical levelling (e.g. Milroy 2002, Trudgill 2011). We assume that this finding is related to the fact that more data are available from the former region than from the latter one, due to a denser distribution of the locations. However, further research is necessary to corroborate this hypothesis.

There are still some other shortcomings that should be addressed in follow-up research. First, vagueness was operationalized by counting how often the lexical items that occur for the target concept are used for other concepts in the same semantic field as well. Although we calculated lexical non-uniqueness per semantic field and per dictionary to reduce the chance of polysemy, this method does not completely eliminate polysemy in the datasets. Follow-up research can take into account the logical, linguistic and definitional tests that have been proposed in cognitive semantics to disentangle polysemic readings from vague ones (for an overview and problems, see Geeraerts 1993, 2015, Lewandowska-Tomaszczyk 2007 and Gries 2015). Additionally, automatic calculations of semantic similarity between lexical items can be obtained by considering the formulation of the questions used in the questionnaires, which are available in the datasets, as an operationalization of the meaning of each lexical item.

Second, additional operationalizations of the predictor variables can be envisaged. First, other measures can be used to gauge the degree to which a concept is salient. For instance, follow-up studies could complement the measures of salience used in this paper by relying on linguistic frequency data. However, as the data in the WBD and WLD represent the dialect lexicon from the beginning of the $20^{\text {th }}$ century and contain a relatively large amount of concepts that have, meanwhile, become obsolete or, at the least, less frequent, large, highly diversified and historical datasets should be used for this purpose. Alternatively, the frequency of a concept in the environment of the dialect users can be gauged by relying on non-linguistic, external data (see for instance Franco and Geeraerts Forthcoming). Since we calculate vagueness, salience and proneness to affect using supralocal measures (e.g. the total number of multi-word expressions or hapaxes or the total number of non-unique variants in an entire dialect area for a specific concept), we neglect the fact that these concept characteristics need not be homogeneous throughout the speech community. It may be the case that social and geographical 
variation on a smaller scale impacts the amount of diversity in the Brabantic and Limburgish dialects as well.

Overall, we contribute to research in Cognitive Sociolinguistics by showing that 'variation through meaning' affects the structure of lexical variation. We note an interaction between the kind of concept that is expressed and the variation of its expression: the degree of lexical variation for a given concept is not only determined by external factors like geography, but also by the very nature of the concept. The results that were obtained open up new perspectives for research in CL. First, we show how our usagebased approach, using naturalistic data that were systematically collected on a large scale, can advance research in $\mathrm{CL}$ methodologically. We offer varied and innovative ways of gauging properties of concepts and of the lexical variants that occur for these concepts, which can also be applied to other types of data. Second, we show that taking a CL perspective to dialectological variation is beneficial for both strands of research. On the one hand, the usage-based nature of $C L$ helps to shift the focus of traditional studies in dialectology from language structure to language use. More importantly, however, although some dialectological case studies exist in CL, they are not manifold (e.g. Swanenberg 2000, Szelid and Geeraerts 2008). We demonstrate that examining the structure of linguistic variation in dialectological data can provide the $\mathrm{CL}$ paradigm with new insights into the relationship between meaning, culture and conceptualization. Finally, in line with the social turn in CL (e.g. Croft 2009, Dąbrowska and Divjak 2015, Geeraerts 2005, Harder 2003, Kemmer and Barlow 2000, Schmid 2016), we show that paying attention to variation within one language offers a more comprehensive picture of the features that may influence linguistic variation. Although recent studies in $\mathrm{CL}$ on lexical diversity across languages emphasize the importance of culture (e.g. Majid and Burenhult 2014, Sinha and Jensen de López 1999), the interaction between lectal features and variation in lexical diversity within one language had not yet been systematically examined. An additional question is, then, whether meaning-related characteristics also affect other flavours of lexical variation. Speelman and Geeraerts (2008) already showed that taking the concept characteristics into account provides a better picture of the dialectometric distance between dialects. Follow-up studies can be envisaged that, for instance, examine the impact of these features on differently stratified varieties: perhaps concept characteristics also correlate with the amount of lexical diversity found across unrelated languages. Further, it may be the case that concepts that show more lexical diversity from the synchronic perspective taken in this paper, are also characterized by a higher speed of lexical change.

\section{Acknowledgements}

The authors are grateful to three anonymous reviewers and to the editorial board for their useful suggestions to an earlier version of this paper. This study was supported by the Research Foundation Flanders (FWO, grant no. G042114N). 


\section{References}

Allan, Keith \& Kate Burridge. 1988. Euphemism, dysphemism, and cross-varietal synonymy. La Trobe Working Papers in Linguistics 1. 1-16.

Allan, Keith \& Kate Burridge. 2006. Forbidden words: Taboo and the censoring of language. Cambridge: Cambridge University Press.

Berlin, Brent. 1978. Ethnobiological classification. In Eleanor Rosch \& Barbara B. Lloyd (eds.), Cognition and categorization, 9-26. New York: Wiley.

Berlin, Brent, Dennis E. Breedlove \& Peter H. Raven. 1973. General principles of classification and nomenclature in folk biology. American Anthropologist 75(1). 214-242.

Brysbaert, Marc, Michaël Stevens, Simon De Deyne, Wouter Voorspoels \& Gert Storms. 2014. Norms of age of acquisition and concreteness for 30,000 Dutch words. Acta Psychologica 150. 80-84.

Brysbaert, Marc, Paweł Mandera, Samantha McCormick \& Emmanuel Keuleers. 2018. Word prevalence norms for 62,000 English lemmas. Behavior Research Methods. 1-13.

Cornips, Leonie, Jos Swanenberg, Wilbert Heeringa \& Folkert De Vriend. 2016. The relationship between first language acquisition and dialect variation: Linking resources from distinct disciplines in a CLARIN-NL project. Lingua 178. 32-45.

Croft, William. 2009. Toward a social cognitive linguistics. In Vyvyan Evans \& Stéphanie Pourcel (eds.), New directions in Cognitive Linguistics, 395-420. Amsterdam \& Philadelphia: John Benjamins.

Dąbrowska, Ewa \& Dagmar Divjak. 2015. Introduction. In Ewa Dąbrowska \& Dagmar Divjak (eds.), Handbook of Cognitive Linguistics (Handbücher zur Sprach- und Kommunikationswissenschaft / Handbooks of Linguistics and Communication Science 39), 1-9. Berlin \& Boston: De Gruyter Mouton.

Daems, Jocelyne, Kris Heylen \& Dirk Geeraerts. 2015. Wat dragen we vandaag: Een hemd met blazer of een shirt met jasje? Convergentie en divergentie binnen Nederlandse kledingtermen [What to wear today: a shirt with a blazer or a shirt with a jacket? Convergence and divergence in Dutch clothing terminology]. Taal en Tongval: Variation in the Low Countries 67(2). 307-342.

Franco Karlien \& Dirk Geeraerts. Forthcoming. Botany meets lexicology: The relationship between experiential salience and lexical diversity. In: Janice Fon (ed.), Dimensions of diffusion and diversity (Cognitive Linguistics Research 63), 113-146. Berlin: De Gruyter Mouton.

Geeraerts, Dirk. 1993. Vagueness's puzzles, polysemy's vagaries. Cognitive Linguistics 4(3). 223-272.

Geeraerts, Dirk. 2005. Lectal variation and empirical data in Cognitive Linguistics. In Sandra Peña Cervel \& Francisco Ruiz de Mendoza Ibáñez (eds.), Cognitive linguistics. Internal dynamics and interdisciplinary interactions (Cognitive Linguistics Research 32), 163-189. Berlin \& New York: De Gruyter Mouton.

Geeraerts, Dirk. 2015. Sense individuation. In Nick Riemer (ed.), The Routledge handbook of semantics, 233-247. London: Routledge.

Geeraerts, Dirk. 2017. Entrenchment as onomasiological salience. In Hans-Jörg Schmid (ed.), Entrenchment and the psychology of language learning. How we reorganize and adapt linguistic knowledge (Language and the Human Lifespan 3), 153-174. Berlin \& Boston: De Gruyter Mouton.

Geeraerts, Dirk, Stefan Grondelaers \& Peter Bakema. 1994. The structure of lexical variation: Meaning, naming, and context (Cognitive Linguistics Research 5). Berlin: De Gruyter Mouton.

Geeraerts, Dirk, Stefan Grondelaers \& Dirk Speelman. 1999. Convergentie en divergentie in de Nederlandse woordenschat: Een onderzoek naar kleding-en voetbaltermen [convergence and 
divergence in the Dutch lexicon: a study on clothing and soccer terminology]. Amsterdam: Meertens Institute.

Geeraerts, Dirk \& Dirk Speelman. 2010. Heterodox concept features and onomasiological heterogeneity in dialects. In Dirk Geeraerts, Gitte Kristiansen \& Yves Peirsman (eds.), Advances in Cognitive Sociolinguistics (Cognitive Linguistics Research 45), 23-39. Berlin: De Gruyter Mouton.

Geeraerts, Dirk, Gitte Kristiansen \& Yves Peirsman (eds.). 2010. Advances in Cognitive Sociolinguistics (Cognitive Linguistics Research 45). Berlin: De Gruyter Mouton.

Gorman, Aloysia M. 1961. Recognition memory for nouns as a function of abstractness and frequency. Journal of Experimental Psychology 61(1). 23-29.

Gries, Stefan Th. 2015. Polysemy. In Ewa Dąbrowska \& Dagmar Divjak (eds.), Handbook of Cognitive Linguistics (Handbücher zur Sprach- und Kommunikationswissenschaft / Handbooks of Linguistics and Communication Science 39), 472-490. Berlin \& Boston: De Gruyter Mouton.

Grieve, Jack, Dirk Speelman \& Dirk Geeraerts. 2011. A statistical method for the identification and aggregation of regional linguistic variation. Language Variation and Change 23(2). 193-221.

Hallgren, Kevin A. 2012. Computing inter-rater reliability for observational data: An overview and tutorial. Tutorials in Quantitative Methods for Psychology 8(1). 23-34.

Harder, Peter. 2003. The status of linguistic facts: Rethinking the relation between cognition, social institution and utterance from a functional point of view. Mind \& Language 18(1). 52-76.

Hargis, Charles H. \& Edward E. Gickling. 1978. The function of imagery in word recognition development. The Reading Teacher 31(8). 870-874.

Heylen, Kris \& Tom Ruette. 2013. Degrees of semantic control in measuring aggregated lexical distances. In Lars Borin \& Anju Saxena (eds.), Approaches to measuring linguistic differences (Trends in Linguistics. Studies and Monographs 265), 353-374. Berlin: De Gruyter Mouton.

Kemmer, Suzanne \& Michael Barlow. 2000. Introduction: A usage-based conception of language. In Michael Barlow \& Suzanne Kemmer (eds.), Usage-based models of language, vii - xxviii. Stanford: CSLI Publications.

Keuleers, Emmanuel, Michaël Stevens, Paweł Mandera \& Marc Brysbaert. 2015. Word knowledge in the crowd: Measuring vocabulary size and word prevalence in a massive online experiment. The Quarterly Journal of Experimental Psychology 68(8). 1-62.

Kristiansen, Gitte \& René Dirven (eds.). 2008. Cognitive Sociolinguistics (Cognitive Linguistics Research 39). Berlin \& New York: De Gruyter Mouton.

Labov, William. 1973. The boundaries of words and their meanings. In Charles-James N. Bailey \& Roger W. Shuy (eds.), New ways of analyzing variation in English, 340-371. Washington: Georgetown University Press.

Lakoff, George \& Mark Johnson. 1980. Metaphors we live by. Chicago: University of Chicago Press. Langacker, Ronald W. 1987. Foundations of Cognitive Grammar. Volume 1: Theoretical prerequisites. Stanford: Stanford University Press.

Levshina, Natalia. 2015. How to do linguistics with R: Data exploration and statistical analysis. Amsterdam: John Benjamins.

Lewandowska-Tomaszczyk, Barbara. 2007. Polysemy, prototypes and radial categories. In Dirk Geeraerts \& Hubert Cuyckens (eds.), The Oxford handbook of Cognitive Linguistics, 139-169. Oxford: Oxford University Press. 
Lillo, Antonio. 2009. Drunk: The definitive drinker's dictionary. International Journal of Lexicography, 23(2). 242-245.

Majid, Asifa \& Niclas Burenhult. 2014. Odors are expressible in language, as long as you speak the right language. Cognition 130(2). 266-270.

Milroy, Lesley. 2002. Introduction: Mobility, contact and language change. Working with contemporary speech communities. Journal of Sociolinguistics 6(1). 3-15.

Moors, Agnes, Jan De Houwer, Dirk Hermans, Sabina Wanmaker, Kevin Van Schie, Anne-Laura Van Harmelen, Maarten De Schryver, Jeffrey De Winne \& Marc Brysbaert. 2013. Norms of valence, arousal, dominance, and age of acquisition for 4300 Dutch words. Behavior Research Methods 45(1). 169-177.

Paivio, Allan. 1986. Mental representations: A dual coding approach (Oxford Psychology Series 9). New York: Oxford University Press.

Pickl, Simon. 2013. Lexical meaning and spatial distribution. Evidence from geostatistical dialectometry. Literary and Linguistic Computing 28(1). 63 -81.

Pütz, Martin, Justyna A. Robinson \& Monika Reif (eds.). 2014. Cognitive Sociolinguistics: Social and Cultural Variation in Cognition and Language Use (Benjamins Current Topics 59). Amsterdam: John Benjamins.

Rosch, Eleanor. 1978. Principles of categorization. In Eleanor Rosch \& Barbara B. Lloyd (eds.), Cognition and categorization, 27-48. New York: Wiley.

Schmid, Hans-Jörg. 2016. Why Cognitive Linguistics must embrace the social and pragmatic dimensions of language and how it could do so more seriously. Cognitive Linguistics 27(4). 543-557.

Sinha, Chris \& Kristine Jensen de López. 2001. Language, culture and the embodiment of spatial cognition. Cognitive Linguistics 11(1-2). 17-41.

Soares da Silva, Augusto. 2010. Measuring and parameterizing lexical convergence and divergence between European and Brazilian Portuguese. In Dirk Geeraerts, Gitte Kristiansen \& Yves Peirsman (eds.), Advances in Cognitive Sociolinguistics (Cognitive Linguistics Research 45), 41-83. Berlin: De Gruyter Mouton.

Speelman, Dirk \& Dirk Geeraerts. 2007. De structuur van lexicale onzekerheid [the structure of lexical insecurity]. Taal \& Tongval Themenumber 20. 47-61.

Speelman, Dirk \& Dirk Geeraerts. 2008. The role of concept characteristics in lexical dialectometry. International Journal of Humanities and Arts Computing 2(1-2). 221-242.

Speelman, Dirk, Stefan Grondelaers \& Dirk Geeraerts. 2003. Profile-based linguistic uniformity as a generic method for comparing language varieties. Computers and the Humanities 37(3). 317-337.

Swadesh, Morris. 1955. Towards greater accuracy in lexicostatistic dating. International Journal of American Linguistics 21(2). 121-137.

Swanenberg, Jos. 2000. Lexicale variatie cognitief-semantisch benaderd: Over het benoemen van vogels in Zuid-Nederlandse dialecten [lexical variation from a cognitive-semantic perspective: on naming birds in the Southern Dutch dialects]. Nijmegen: Radboud University dissertation.

Swanenberg, Jos. 2004. Kolbloemen, bloedpaters en manebladen versus zoetelief en luitentuit. Bronnen van lexicale variatie in de Brabantse flora en fauna ['kolbloemen', 'bloedpaters' and 'manebladen' versus 'zoetelief' and 'luitentuit'. Sources of lexical variation in the Brabantic flora and fauna]. Taal \& Tongval 56. 19-47. 
Swanenberg, Jos 2010. Als het beestje maar een naam heeft [as long as the animal has a name]. In Johan Rooryck, Jeroen Van Craenenbroeck, Guido Vanden Wyngaerd, Johan De Caluwe \& Jacques Van Keymeulen (eds.), Voor Magda: Artikelen voor Magda Devos bij haar afscheid van de Universiteit Gent, 561-568. Gent: Academia Press.

Szelid, Veronika \& Dirk Geeraerts. 2008. Usage-based dialectology. Emotion concepts in the Southern Csango dialect. Annual Review of Cognitive Linguistics 6(1). 23-49.

Tadmor, Uri. 2009. Loanwords in the world's languages: Findings and results. In Martin Haspelmath \& Uri Tadmor (eds.), Loanwords in the world's languages, 55-75. Berlin \& Boston: De Gruyter Mouton.

Trudgill, Peter. 2011. Social structure, language contact and language change. In Ruth Wodak, Barbara Johnstone \& Paul Kerswill (eds.), The SAGE handbook of sociolinguistics, 236-248. Los Angeles: Sage. WBD = Woordenboek van de Brabantse dialecten [dictionary of the Brabantic dialects]. 1967-2005. Assen: Van Gorcum / Amsterdam: Gopher.

Weijnen, Antonius A. 1966. Nederlandse Dialectkunde [Dutch dialectology] (Studia Theodisca 10). Assen: Van Gorcum.

Wieling, Martijn, Clive Upton \& Ann Thompson. 2014. Analyzing the BBC voices data: Contemporary English dialect areas and their characteristic lexical variants. Literary and Linguistic Computing 29(1). 107-117.

WLD = Woordenboek van de Limburgse dialecten [dictionary of the Limburgish dialects]. 1983-2008. Assen: Van Gorcum / Amsterdam: Gopher.

Zenner, Eline, Dirk Speelman \& Dirk Geeraerts. 2012. Cognitive Sociolinguistics meets loanword research: Measuring variation in the success of anglicisms in Dutch. Cognitive Linguistics 23(4). 749-792.

Zuur, Alain F, Elena N. Ieno, Neil J. Walker, Anatoly A. Saveliev \& Graham M. Smith. 2009. Mixed effects models and extensions in ecology with $R$ (Statistics for Biology and Health). New York: Springer. 